\title{
Strategic planning by the Iowa chapter of ACRL
}

\author{
By Kathy A. Parsons \\ Reference Librarian \\ Iowa State University
}

\section{How one chapter has followed ACRL's lead to provide direction for its organization and members.}

$\mathbf{W}$ ho are we? Why are we doing what we are doing? Is there something we should be doing instead? Where should we be going in the future? These are questions many organizations ask themselves at some point in their existence. To help find the answers, many organizations conduct surveys to develop profiles of their members, assess programs offered, and determine if the organization is fulfilling the needs of their members. Next, organizations develop plans to accomplish the goals of their organization and provide direction for their group. This planning process is commonly known as strategic planning. Strategic planning has been defined as "the process of deciding on the objectives of an organization, the use and application of resources, and the policies to achieve these ends."

In 1986 the Association of College and Research Libraries conducted a survey of its members and developed a strategic planning document which is now providing direction for ACRL. ${ }^{2}$ But what

${ }^{1}$ Management Glossary, comp. by $\mathrm{H}$. Johannsen and Andrew Robertson, ed. by E.F.L. Brech (London: Longmans, Green and Co., 1968).

${ }^{2}$ Strategic Planning for ACRL; Final Report of the ACRL Strategic Planning Task Force (Chicago, IL: American Library Association, Association of College and Research Libraries, 1986) (ED 277 about the ACRL chapters? Should they also evaluate their objectives and programs? The answer should be "Yes." Yet a review of the library literature shows that no ACRL chapter has published a study of its members, described the development of a strategic plan for its chapter, or disseminated this information nationally. The purpose of this article is to fill this gap in the literature and describe what one chapter has done to provide direction for its organization and members.

\section{Committee charge and activities}

In 1988, the president of the Iowa Chapter of the Association of College and Research Libraries (ILA/ACRL) formed an Ad Hoc Chapter Strategic Planning Committee to develop a strategic planning document similar to the one produced by ACRL and conduct a survey of the academic librarians in Iowa. The members-Elizabeth Kaschins, Luther College, Chairperson; Linda Good, Iowa Central Community College; Bruce Ohrlund, formerly of St. Ambrose College; Kathy A. Parsons,

386); Strategic Planning (Chicago, IL: American Library Association, Association of College and Research Libraries, Strategic Planning Task Force, n.d.). 
Iowa State University; Lorna Peterson, Iowa State University; and William A. Stoppel, Drake University - were from a variety of public and private university, college, and community college libraries. The planning document was scheduled for completion and review by the chapter's executive council in late 1990.

The committee met for the first time in December 1988 at the annual planning retreat of the Iowa Library Association (ILA). We discussed the purpose of the committee, activities, and documents related to the national ACRL Strategic Planning task force. We decided that we should use the materials the national Task Force had already created as much as possible, especially the strategic planning document. This would provide us with a solid base to begin our tasks and save valuable time. Then the committee evaluated each goal or objective for its applicability to ILA/ACRL. We deleted those goals and objectives that were not relevant to us in Iowa and modified or kept those that were appropriate for Iowa academic librarians. The committee agreed to meet again in the spring after all of us had read the national ACRL Task Force report, evaluated the usefulness of the survey used by the national ACRL Task Force, and examined the rough adjustments we made to the national strategic plan.

Early in 1989, the committee met to discuss the full ACRL Task Force report, review the activities of the first meeting, and determine the mechanics of conducting a survey. We agreed that early in the fall of 1989 we would do a survey of the librarians listed in the 1989-1990 Iowa Academic \& Research Libraries Directory. By surveying all those persons and not just the members of the chapter, we would be able to gather data about those who chose not to join the chapter as well as members. The committee decided to adapt, if possible, the survey sent out by the national ACRL Task Force and any other surveys we could find in order to avoid duplication of effort. Then the committee divided itself into two groups. One group worked on the survey to be sent to academic librarians, and the other group continued to develop the planning document for ILA/ACRL.

A progress report was given at the ILA/ACRL spring conference in April 1989 by the chairperson. In this report, the committee discussed the activities completed to date and encouraged the librarians present to complete the survey that would be mailed in the early fall. By June 1989 a rough draft of the survey was sent to committee members for comments. After heing revised accordingly, the survey and accompanying materials were prepared for mailing in early September.

Another progress report was presented at the ILA annual conference in October. This report contained the return rates for the survey and a request for any surveys not yet returned, since the analysis had not been completed. In late October 1989, the surveys were analyzed for the committee by the Educational Testing Service at Iowa State University. Due to the magnitude of responses, the committee reallocated some job assignments. The compilation of the written responses was completed by the chairperson.

At the ILA annual planning retreat in early November 1989, the committee presented the results of the quantitative questions to the executive council of ILA/ACRL. The council was pleased with the work completed thus far and suggested that the results be sent out to all the librarians who originally received the survey in addition to being distributed at the 1990 ILA/ACRL spring conference.

In April 1990, the committee met at Iowa State University to work on the draft version of the strategic plan and to discuss who should receive the written comments. We sent the ILA/ACRL program committee the suggestions for new programs and the chapter's executive council any membership or policy concerns that appeared in the written responses. At the ILA/ACRL spring conference, the results of the survey and the draft version of the strategic plan were distributed to the conference participants.

Currently, the committee is writing the final version of the strategic plan. When it is completed, it will be submitted to the chapter's executive council for approval. The plan will then be published in Catalyst, the newsletter of the Iowa Library Association.

\section{Methodology}

A survey instrument consisting of 45 multiple choice questions and five short answer questions was developed. This was sent to the 409 academic librarians and other staff listed in the Iowa Academic \& Research Libraries Directory for 1989-1990. Included in this directory are college, community college, private and public university, and special libraries. A total of 230 usable surveys was returned, for a response rate of $56 \%$. There was no formal follow-up to those people who did not return the survey. The results from the survey were coded onto optical scoring sheets and subsequently analyzed by the Iowa State University Educational Testing Service. For a copy of the questionnaire and the results, contact the author.

\section{Results}

The results showed that the average academic librarian in Iowa is similar to her national counterpart, with a few exceptions. The typical academic librarian in Iowa is female ( $73 \%$ ), as is the respon- 
dent to the national survey $(62.5 \%)$. She is $31-50$ years old ( $55 \%$ for Iowa, $56 \%$ for the nation) and has earned an MLS Degree $(60 \%, 88 \%)$. She works in a research institution $(40 \%, 51 \%)$, and her area of work is primarily administration $(24 \%, 28 \%)$ or public services $(23 \%, 29 \%)$ or technical services $(20 \%, 11 \%)$. In Iowa, she has faculty status $(58 \%)$ and the same ranking as teaching faculty $(50 \%)$, but the promotion and tenure requirements are not the same ( $45 \%)$. In contrast, the typical respondent to the national survey does not have the same ranking as the teaching faculty (54\%). Respondents to the national survey were evenly split ( $48 \%$ and $48 \%$ ) on the question of whether their eligibility for tenure was exactly like that of other faculty members.

The Iowa academic librarian is more likely to receive financial support for professional travel (97\%) than her national counterpart (88\%). She has attended the ILA fall conference (63\%), the ILA/ACRL spring conference $(52 \%)$, and at least one ALA Conference (58\%). However, she has not attended a national ACRL conference $(78 \%)$. She is satisfied with the ILA fall conference and the ILA/ACRL spring conference programs ( $45 \%$ for both). The typical respondent to the national ACRL survey does not attend regional ACRL chapter meetings $(59 \%)$ or the national ACRL conference $(84 \%)$, but she attends ALA conferences $(66 \%)$

The typical academic librarian in Iowa is a member of ILA (72\%), ILANACRL (67\%), ALA (56\%), and other related associations (47\%). She does not belong to ALA/ACRL (47\%), other ALA divisions or round tables (43\%), or other ILA divisions, forums, or round tables (47\%). She has belonged to ALA for 5-10 years $(25 \%)$ as well as ACRL (18\%). She has been a member of ILA for $1-4$ years $(34 \%)$ and ILA/ACRL for $1-4$ years (40\%). She has not been active on committees of the library associations, held office in those associations, or voted in the last ILA/ACRL election (53\%). The typical national respondent has belonged to ALA/ACRL for $0-4$ years $(46 \%)$ and has voted in the ALA/ACRL elections (69\%).

\section{Dues and organizational structure}

The respondents were asked to comment on three issues currently of interest to the chapter's executive council. The first dealt with the growing size of the organization and whether sections organized by type of library were needed. The results were inconclusive; $40 \%$ of the responses were affirmative, $41 \%$ were negative, and $19 \%$ were blank. The second issue was the creation of an additional scholarship fund to support travel to a national meeting. Of the respondents, $47 \%$ would support such a fund, $40 \%$ would not, and $13 \%$ left the question blank.
The third issue was the dues structure of the chapter. Currently the chapter does not charge dues. The majority of the respondents $(73 \%)$ were aware of this policy; the remaining $24 \%$ did not realize that membership in the chapter is free. To the question, "Would you still belong if dues were assessed?" $73 \%$ said "Yes," $17 \%$ said "No," and 17\% did not answer the question. Of those who answered positively, $38 \%$ said they would be willing to pay $\$ 5.00$ in dues.

\section{Suggestions and insights}

Many insights were gained from the written responses. The members were asked to comment on their experience as an officer in ILA/ACRL, give suggestions for programs for the ILA/ACRL spring and ILA fall conferences, explain why they are active or not active in ILA, suggest activities the chapter could discontinue, and suggest activities that could be added.

It was found that respondents valued their experience as an officer in ILA/ACRL for the opportunities it provided for leadership and growth and for the contributions they were able to make to the profession. Many found holding offices rewarding but lots of work, some found the lack of feedback from membership discouraging. The overwhelming majority of the 25 responses was positive.

There were numerous suggestions for conference programs. Some of the more popular ideas were $\mathrm{BI}$; collection development issues; copyright laws; how new technologies affect library policies, staff, and patrons; and staff recruitment, retention, and development. Some respondents even suggested speakers. These suggestions have since been given to the ILA/ACRL Program Committee.

\section{Involvement issues}

The question that received the most comment was the one that requested reasons for involvement or noninvolvement in ILA. Of the 230 surveys returned, only 64 surveys did not contain a response. The most common reasons given for continuing involvement were professional interaction, professional responsibility, professional growth, and the high quality of conferences. Reasons given for not being involved in ILA were "too public library oriented," "other organizations meet my needs," and "I do not have an MLS degree." In addition, there were several suggestions on how to increase membership in ILA. They included having more sessions for technical services and science librarians, lowering dues, holding meetings in the southeast or east central part of the state, and accepting credit cards for the payment of dues.

The question about activities that could be discontinued elicited many "do not know" and "none" 
responses, while a few comments involved reexamining the existing committee structure. However, the request for activities in which the chapter should be involved provided the executive council with many useful suggestions including preconferences, continuing education courses, a newsletter for the chapter, educational tours, and retreats for leaders and nonleaders.

\section{Problems}

In studying the results of the survey, the committee discovered flaws in many of the questions. These flaws resulted in some blank responses. The committee realized that the respondents were not given the option of saying "Unsure," "No, I would not belong," and "I did not attend" for many of the questions. Even the questions about longevity of membership contained errors. We neglected to include $11-15$ years as an option. Surprisingly, the presence of blanks did not affect greatly the results for the majority of questions. However, in one instance the lack of an option to say "No, I would not belong" created different results when calculated without the blanks. The results from the question regarding how much dues a person would be willing to pay to belong to ILA/ACRL had completely different percentages when the blanks were removed. More careful proofreading of the survey would have prevented this problem, especially if it had been performed by someone not associated with the committee or the survey.

\section{Conclusions}

The outcome of the committee's work has been an increased awareness of the needs of academic librarians in Iowa and the development of a strategic plan that will help guide the chapter into the $1990 \mathrm{~s}$. It is recommended that the Iowa chapter continue to evaluate its programs and solicit the ideas of both members and nonmembers in order to create an organization that changes to meet changing needs. It would be interesting to see other ACRL chapters evaluate their programs and disseminate this information.

\section{Draft of a strategic plan for the Iowa chapter of ACRL (April 16, 1990)}

\section{Mission statement}

The mission of the Iowa chapter of the Association of College and Research Libraries (ILA/ ACRL) is to foster the profession of academic and research librarianship and to enhance the ability of academic and research libraries in the state to serve effectively the library and the information needs of current and potential library users.

\section{The plan}

The plan will consist of four goals, each of which will have a varying number of subgoals and objectives. The full plan will include strategies for implementation for each objective, assignment of responsibility, an assessment of the resources needed and suggestions for the year of implementation.

\section{Goals, subgoals, and objectives}

- GOAL I: To contribute to the total professional development of academic and research librarians.

- Subgoal A: To sponsor and encourage opportunities for academic and research librarians to update existing competencies, learn requisite new skills, and gain awareness of the state of the art.

- Objective 1: Maintain moderate cost to participate in ILA/ACRL professional development activities. Objective 2: Expand the number of opportunities for academic and research librarians to participate in professional development activities, especially at the state or local level. Objective 3: Increase financial support for programs and projects. Objective 4: Continue an ongoing process for assessing educational needs and evaluating the success of ILA/ACRL professional development activities. Objective 5: Coordinate ACRL continuing education programs with those of ILA.

- Subgoal B: To promote a sense of professional identity and peer reinforcement among academic and research librarians.

- Objective 1: Review the procedures for administering awards to ensure that they are effectively providing a sense of professional identity and peer reinforcement.

- GOAL II: To enhance the capability of academic and research librarians and libraries to serve the needs of users.

- Subgoal A: Encourage the use and dissemination of library professional organization standards and guidelines throughout the Iowa higher education community.

- Objective 1: Increase librarians' awareness of library professional organization standards and guidelines. Objective 2: Increase the dissemination of library professional organization standards and guidelines throughout the lowa higher education community. Objective 3 : Increase librarians' understanding of the accreditation process and the role of the library in institutional accreditation. Objective 4: Increase dissemination of Iowa academic and research libraries' rankings in quantitative assessments of libraries as defined by professional organiza- 
tions. Objective 5: Educate the community about how these standards and guidelines can be used to enhance the capability of librarians and libraries to serve the needs of users.

- Subgoal B: To identify, explore, and act on problems and issues facing academic and research libraries.

- Subgoal C: To encourage innovation in library operations and services.

- GOAL III: To promote and speak for the interests of academic and research librarianship.

- Subgoal A: To enhance awareness of the role of academic and research librarians and libraries among nonlibrary professionals and organizations (higher education associations, scholarly and professional societies, etc.) and to develop effective working relationships with them.

- Objective 1: Create opportunities for academic librarians to interact with other professionals in the Iowa academic community. Objective 2: Develop new alliances with other professional organizations.

- Subgoal B: To monitor and speak out on government and private sector activities likely to affect academic and research librarianship, including legislation and fiscal and political support at all levels.

- Objective 1: Establish ILA as the authority to speak for the academic library profession on issues of importance to higher education and academic libraries. Objective 2: Strengthen membership efforts to affect and influence government and private sector activities, including legislation, funding, and quality higher education.

- Subgoal C: To support and participate in the recruitment and retention of outstanding persons to the field of academic and research librarianship.

- Objective 1: Develop mechanisms to attract candidates of high quality. Objective 2: Support the recruitment of members of underrepresented groups to academic librarianship. Objective 3: Promote the adoption of compensation plans and personnel policies that enhance the status, professional development, and working conditions of academic librarians.
- Subgoal D: Enhance communication between academic and research librarians and the graduate library education program to meet needs of academic and research librarians and libraries.

- GOAL IV: To promote study, research, and publication relevant to academic and research librarianship.

- Subgoal A: Encourage improvement in research skills.

- Objective 1: Develop incentives or programs to encourage librarians to engage in research.

- Subgoal B: Encourage research projects, report works in progress, and disseminate research results.

- Subgoal C: To advance the professional knowledge of academic librarians through an effective use of existing Iowa library publications and programs.

- Objective 1: Review ILA, state library, and other Iowa library publication programs to ensure that they support association goals and can facilitate the dissemination of information that meets the needs of academic librarians. Objective 2: Encourage conference programs that include presentations of research results by Iowa librarians.

\section{Strategic management directions}

1. Position the Iowa chapter of ACRL as the most significant Iowa association of academic and research libraries, librarians, and librarianship. ILA/ACRL shall be considered the association that represents, speaks for, asserts the interests of, and assists Iowa academic librarians in reaching their goals.

2. Seek new members through a variety of recruitment techniques, while extending efforts to retain present members, including regular assessments of member needs.

3. Support all elected and appointed officers and committee members in fulfilling their leadership roles through programs of orientation and planning.

4. Work collaboratively with other ILA units and academic and research library consortia in lowa and the region for the good of librarianship as a whole.

Committee work and offices held by academic librarians in Iowa

\begin{tabular}{lrrlrr}
\hline \hline Served on: & Yes & No & Held office in: & Yes & No \\
\hline ALA committees & $11 \%$ & $79 \%^{\circ}$ & Held ALA office & $3 \%$ & $88 \%$ \\
ACRL committees & $9 \%$ & $82 \%$ & Held ACRL office & $1 \%$ & $90 \%$ \\
ILA committees & $22 \%$ & $70 \%$ & Held ILA office & $8 \%$ & $85 \%$ \\
ILAACRLcommittees & $25 \%$ & $67 \%$ & Held ILA/ACRL office & $9 \%$ & $83 \%$ \\
Other ALA divisional committees & $13 \%$ & $76 \%$ & Office in other ALA divisions & $7 \%$ & $85 \%$ \\
Other ILA divisional committees & $16 \%$ & $75 \%$ & Office in other ILA divisions & $11 \%$ & $80 \%$ \\
\hline
\end{tabular}

-Total may not add up to $100 \%$ due to blanks. 


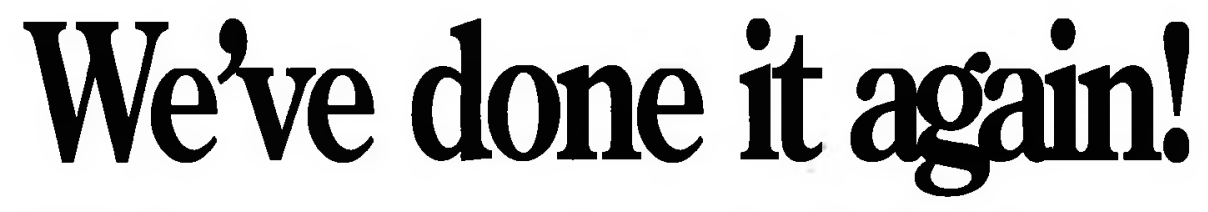

\section{The five most recent years of scientific journal literature...in a single set of volumes.}

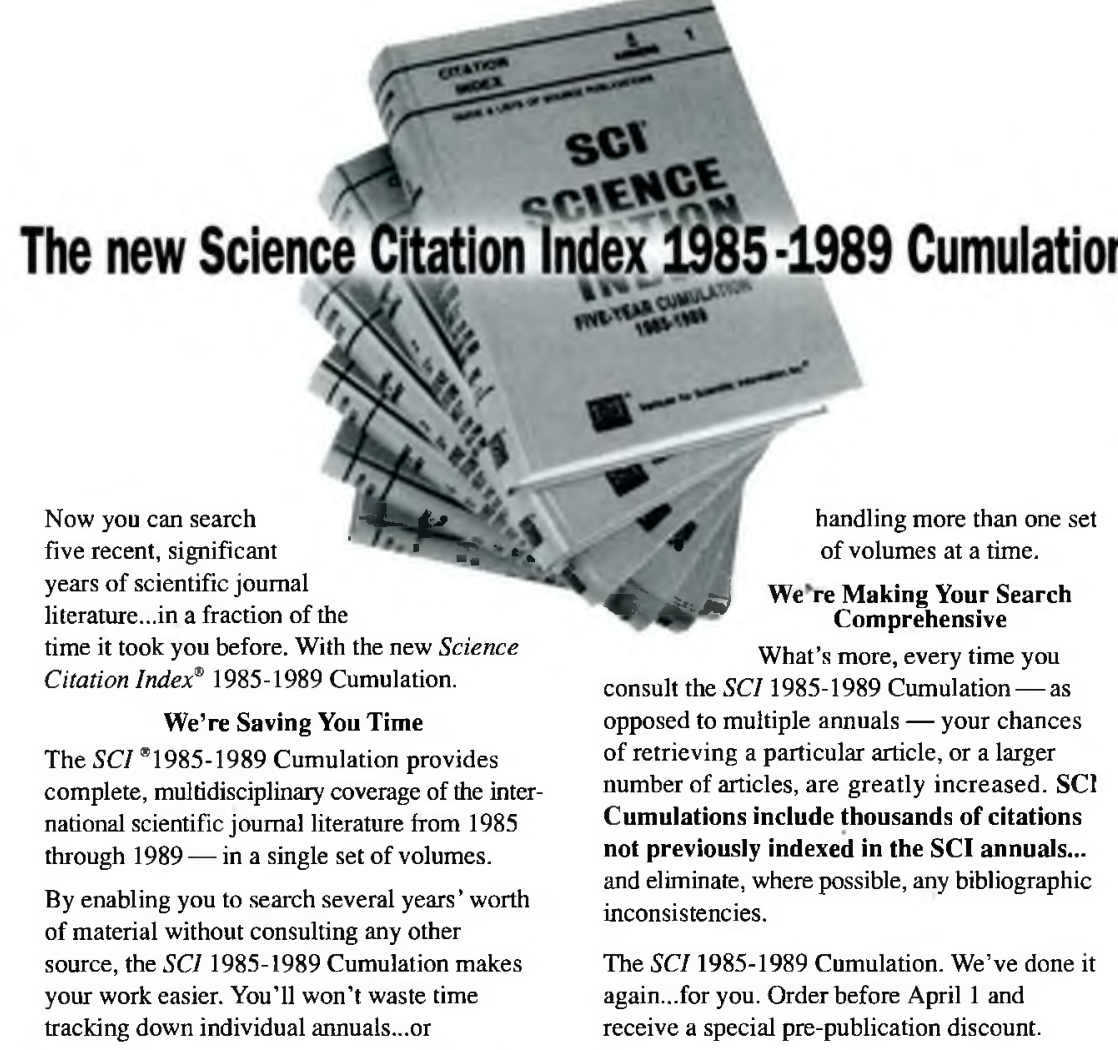

Call 800-336-4474, Operator R-361.

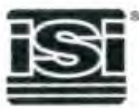

Institute for Scientific Information

3501 Market Street, Philadelphia, PA 19104 European Branch: 132 High Street, Uxbridge, Middlesex UB8 1DP, United Kingdom

\section{The ISI Indexes...Gateway to the Literature of Science}

